\title{
Water deprivation and shock thresholds
}

\author{
ROBERT J. BLANCHARD, MAURICE HAYASHI AND \\ GLORIA REYES, UNIVERSITY OF HAWAII
}

Thirty-two rats, under no deprivation or under $48 \mathrm{~h}$ water deprivation, were given 10 series of 12 different shock intensities, using the method of constant stimuli. Their reactions were classified into several categories. None of the group differences on these categories approached statistical significance, indicating that water deprivation does not alter thresholds for electric foot shock.

Griffiths (1962) has reported that food and water deprivation lead to a reliable decrease in reactivity to electric foot shock. However, Blanchard \& Blanchard (1966) found no difference between hungry and nonhungry Ss' flinch or jump thresholds to foot shock. They did find a significant inverse correlation between percentage weight loss and vocalization thresholds for hungry Ss, but the percentage weight loss ranges of that study (17-30\%) would not have been applicable to Griffiths' Ss, which were deprived for a single 12 or $24 \mathrm{~h}$ period. Also, weight loss should not have been a factor in the behavior of the 12 or $24 \mathrm{~h}$ water deprived Ss.

If water deprivation in contrast to food deprivation, does decrease reactivity to foot shock, then it becomes extremely difficult to make meaningful comparisons between passive avoidance results in situations in which the punished response was previously rewarded by water as opposed to food. Also, Ley (1965) has found that both food and water deprivation enhance performance in an active avoidance situation. It is difficult to reconcile this finding with the notion of thirst produced deficits in reactivity to shock. The present study was an attempt to determine if water deprivation does, in fact, alter flinch, jump, or vocalization thresholds to electric foot shock.

\section{Methol}

The Ss were 32 female Holtzman derived rats from the colony maintained by the University of Hawaii Psychology Department. They were 90-120 days old at the beginning of the experiment. Sixteen randomly selected Ss were weighed and deprived of water for $48 \mathrm{~h}$ prior to the experiment. They were also weighed immediately before being placed in the shock chambers. The remaining $16 \mathrm{Ss}$ were given ad lib access to food and water, but were weighed at the same times as the deprived animals.

During testing, each $S$ was placed in a GraysonStadler operant conditioning chamber, and allowed 3-5 $\min$ to explore. Shocks were presented through an E1064GS shocking source. Twelve stimulus intensities $(.05, .10, .20, .30, .40, .50, .60, .80,1.00,1.30,1.60$, and $2.00 \mathrm{~mA}$ ) were used. Stimuhus duration was .2 $\mathrm{sec}$, and the average interstimulus interval was $10 \mathrm{sec}$. Order of presentation was random within each block of trials, with each stimulus intensity being presented once per trial block, for a total of 10 trial blocks. Jumps, flinches, and vocalizations were judged according to the criteria used by Blanchard \& Blanchard (1966). The E who judged these responses did not know the stimulus intensity on any given trial, or the S's experimental condition.

\section{Results and Discussion}

Figure 1 presents the proportion of flinch and jump responses of the two groups as a function of stimulus intensity. It is apparent that the curves for thirsty and non-thirsty animals are extremely similar. For each S, jump, flinch, and vocalization thresholds were computed by linear interpolation to the intensity at which the appropriate response was emitted on $50 \%$ of the trials. The thirsty group's flinch, jump, and vocalization thresholds were $.13, .53$, and $.50 \mathrm{~mA}$, respectively, while the corresponding thresholds for the non-thirsty group were $.12, .53$, and $.48 \mathrm{~mA}$. None of the threshold group differences approached statistical significance. It might also be noted that these threshold values were very similar to those obtained by Blanchard \& Blanchard (1966) for sated rats (flinch $=.14 \mathrm{~mA}$; jump $=.54 \mathrm{~mA}_{\text {i }}$ vocalization $=.44 \mathrm{~mA}$ ).

Thus the present findings, in contrast to those of Griffiths (1962), indicate that thirst does not alter the immediate reactions of rats to electric foot shock. One possible procedural difference which may have affected the thresholds for thirsty as opposed to non-thirsty Ss is that Griffith immersed the shock cages in water, to

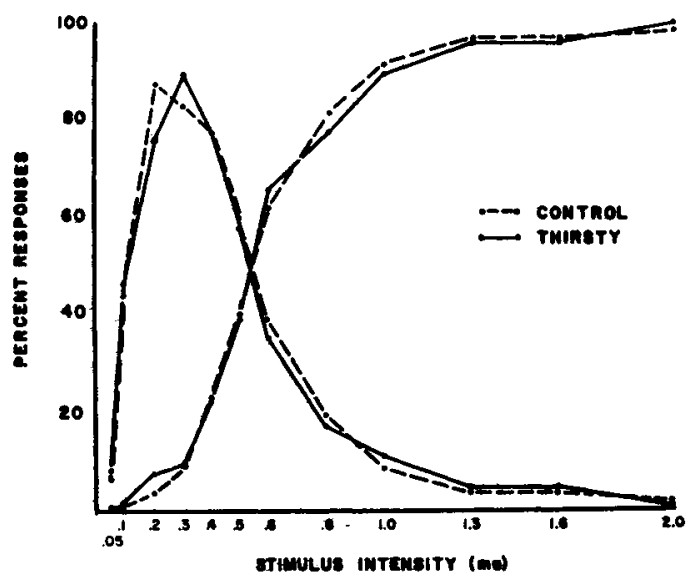

Fig. 1. The proportion of flinch (peak at left) and flinch (maximum at right) responses for thirsty and non-thirsty rats, as \& function of stimulus intensity. 
which alum was added. It is possible that alum drinking, which was undoubtedly more frequent for the deprived Ss, may have produced a decrease in vocalization for these groups. Finally, Griffiths' use of urination and defecation as indices of the noxiousness of shock presents problems when making comparisons between deprived and non-deprived Ss.

\section{References}

BLANCHARD, R. J., \& BLANCHARD, D. CAROLYN. Food deprivation and reactivity to shock. Psychon. Sci., 1966, 4, 317-318.

GRIFFITHS, W. J. Effect of food and water deprivation on shock tolerance of albino rats. Psychol. Rep., 1962, 11, 163-166.

LEY, R. Effects of food and water deprivation on the performance of a response motivated by fear. J. exp. Psychol., 1965, 69, 583-589. 